\title{
Near-Death Experiences and the Pursuit of the Ideal Society
}

\author{
Allan Kellehear, Ph.D. \\ La Trobe University
}

ABSTRACT: Up to one half of near-death experiencers report a social and physical realm beyond death. I describe the features of this afterlife society and compare them with previous ideas about the ideal society. I argue that the society so often mentioned by near-death experiencers is a unique type of utopian society. As stories from utopia, near-death experiences (NDEs) serve as inspirational narratives that help us re-evaluate the social world and our place in it. They also help integrate sometimes contradictory paradigms from religion, politics, and science. In this way, NDE narratives may be seen as the latest chapter in a long search for better social ideas about living harmoniously with each other.

For most of this century the social science literature dealing with death and dying has been explicit about one issue: Death is a dark country. Never far away, its major cities are Loss, Grief, and Aloneness. Recently, however, a new viewpoint has emerged. Beyond that first shadowy country lies another, less inhospitable land. Indeed, this is a land of fabulous light and landscape. And in this country the cities are called Learning, Love, and Service. This is the place many people describe when recovering from the near-death experience (NDE).

Less astonishing certainly, but equally intriguing, is the curious paucity of sociological literature about this strange society. Is this society, and its cities and citizenry, the latest, modern notion of paradise? Do these visions and values of the Good Life bespeak a renewed desire for some lost arcadia or golden age? Or do these visions in the

Allan Kellehear, Ph.D., is a Lecturer in Sociology at La Trobe University. Reprint requests should be addressed to Dr. Kellehear at the Department of Sociology, La Trobe University, Bundoora, Victoria 3083, Australia. 
final moments of consciousness reveal, at death's door, a final yearning for utopia?

The aim of this essay is to examine the transcendental features of the NDE that depict another social world beyond this one. I will not attempt here to evaluate the reality of these reports. Rather my purpose is to treat the reports of, and writing about, transcendental NDEs as narratives that may be read and interpreted for their assumptions and allusions about the ideal society.

In this way, I argue that NDEs are social images that, whatever else they may be, belong to the historical and social discourse about the ideal society. The identification and examination of this otherworldly society permit a cultural analysis that furthers our understanding of NDEs as sociological phenomena. If visions of this otherworldly society are prompting people to change their social values and lifestyle, then it is important to understand why. Many of these changes undoubtedly derive from the social and psychological crisis of being near death (Kellehear, 1990). However, another part of this understanding must come from the possibility that the social images of this ideal society may also be prompting or inspiring some of these changes. Furthermore, treating the NDE as part of a discourse about the ideal society makes it possible for us to explore and re-evaluate our social ideas about personal identity, social change, deviance and control, and issues of cultural and social representation. In exploring the transcendental features of the NDE I attempt to answer two questions. First, what kind of ideal society is this society that so many NDErs encounter? Second, how does this conception of the ideal society differ from earlier types?

In developing answers to these two questions I organize the paper in the following manner. The first section will identify the type of NDE in which people report seeing another society. For the purposes of this paper I shall call the society at the center of these reports the "transcendent society." I will then describe the social features of this society such as we know them from various NDE accounts. I draw here mainly on Craig Lundahl's (1981-82) early work in this area. The next section will examine the transcendent society by comparing its features with five types of ideal society as outlined and discussed by J.C. Davis (1981, 1984). In this respect, the early work of Lundahl is extended through the application of Davis' typology of the ideal society. The final section will discuss the transcendent society as a utopia with unique social properties. I argue that, as a utopian form, the transcendent society reawakens the pursuit of the ideal society. This is a pursuit that has largely faltered this century because of several historical and concep- 
tual problems. Many of these difficulties are overcome by the transcendent society.

\section{The Transcendent Society}

The overwhelming majority of reported NDEs are positive experiences. Bruce Greyson (1983) identified three distinct types of positive NDE. These are the cognitive type, which exhibit features such as time distortion, thought acceleration, life review, and sudden understanding; the affective type, which exhibits features such as feelings of joy, cosmic unity, peace, and an experience of light; and the transcendental type, which exhibits features such as encounters with an unearthly realm populated by beings and a "barrier or point of no return" that if crossed would preclude return to life. It is this transcendental type of NDE on which this paper focuses for details of a society beyond death.

Greyson (1983) estimated that $42.7 \%$ of his sample of NDErs experienced the transcendental type of NDE. Michael Sabom (1982), who divided the NDE into two types, the autoscopic and the transcendental type, estimated that over half of his sample of NDErs had encountered some other social world beyond this one. More modest incidences were reported by the Evergreen study (34.5\%) (Lindley, Bryan, and Conley, 1981) and Kenneth Ring's experiencer sample (20\%) (1980). Furthermore, George Gallup (1982) estimated that some eight million Americans may have experienced an NDE. Significant numbers of these are presumably familiar with aspects of the transcendent society.

In the NDE literature descriptions of the transcendent society are often the spectacular finale in an ideal composite portrayal of the NDE. Researchers such as Raymond Moody (1975), Ring (1980), Sabom (1982), Margot Grey (1985), and Carol Zaleski (1987) all developed their analyses by moving from the basic cognitive-affective features of the NDE to the descriptions of an unearthly realm. As with many features of the NDE, the reports of this society are highly similar. This notwithstanding, the details of the transcendent society are admittedly few. As Zaleski (1987) noted, the emphasis in most descriptions is on the message of love, learning, and personal and social transformation. However, as sparse as these details may seem, it is still possible to discern salient features of organization and process that would locate this kind of society in the context of others.

Lundahl (1981-82) provided the most systematic social and physical description of this other world, based on his review of the NDE literature and nine selected accounts of Mormon NDEs. The physical world 
in the NDE is a world of beautiful skies and lush vegetation. Crisscrossed by streams, dotted by lakes, there are also forests, lawns, parks, and gardens that contain flowers of unique and unprecedented beauty (Lundahl, 1981-82). Sight, movement, and mental abilities are increased in capability, allowing greater vision, faster travel, and sharper cognitive ability. Although there appear to be idyllic rural environments, there also appear to be cities and many buildings such as halls, houses, and temples. Cities contain libraries, places of higher learning, and living areas (Lundahl, 1981-82; Elder, 1987; Moody, 1988).

The social climate was described by Lundahl (1981-82) as largely one of contentment, happiness, harmony, and order. It is highly organized and conversely eschews disorder and confusion. Apparently people in this society work; that is, they have occupations that are often tied to some sort of human service industry (Gallup, 1982). Interaction is based on cooperation in general, but sanctions do exist to control deviance (Lundahl, 1981-82).

The social system is stratified, apparently along moral lines. The society is divided into different communities or levels of activity and order based on different degrees of moral progression. Problem groups are confined to certain areas so they are restrained from disrupting the smooth operation of other communities (Lundahl, 1981-82). The means and criteria by which such people are restrained are not clear.

As extraordinary as this description of the transcendent society must seem, it is nevertheless incomplete for another reason aside from the brevity of most NDErs' visits. Other societies with similar characteristics, or other cultural communities within this one single community, also apparently exist. There are suggestions of a transcendent society in Melanesian (Counts, 1983), Indian (Pasricha and Stevenson, 1986), and Chinese (Becker, 1981, 1983; Hermann, 1990) NDE accounts. For example, in the Melanesian version of NDE, the society beyond is also a beautiful and well-ordered place. No cities are reported but instead there are descriptions of villages. In these villages people are also described as working, constructing buildings or participating in traditional song and dance. Social control is also part of the work of this society; Dorothy Counts (1983) reported the trial of a sorcerer.

In most cases, NDErs report their reluctance to leave that wellordered world beyond. As some of Ring's $(1984$, p. 91) respondents expressed it:

"The most depressed, the most severe anxiety I've ever had was at the moment I realized I must return to this earth." 
"I began to realize that I was going to have to leave and I didn't want to leave" [begins to cry].

Not all NDErs feel this strongly about their return. However, even those who desire to return often leave with a sense of regret because they are leaving such a beautiful and attractive place. The extraordinary nature of their story of revival plus their accounts of another realm have also fired the imaginations of millions of nonNDErs.

No doubt that this description of a society is an ideal, indeed idealized, society. The sociological question is now: what kind of ideal society is this?

\section{Davis' Typology of the Ideal Society}

In theoretical terms, the literature examining utopias and other forms of the ideal society tends to fall into two categories. On the one hand, some writers are reluctant to broach the task of definition for fear of excluding some types of society. Frank and Fritzie Manuel (Manuel \& Manuel, 1979) avoided definition of major concepts such as Utopia for fear of obscuring what they argue to be the pluralist nature of utopia (Alexander and Gill, 1984). This is a similar line of argument taken by Krishnan Kumar (1987).

On the other hand, writers such as Davis $(1981,1984)$ argued that definition is not only possible but desirable precisely because of the ambiguity of the concept. Toward this end, Davis provided a typology of ideal societies common in Western history. In this task, Davis maintained that definitions are important for clarity but that they do not have to be distinct and mathematical in construction; they do not have to be airtight. My view of this debate is that it is precision rather than definition that is problematical. Karl Mannheim (1960) provided a very precise distinction between ideological and utopian forms of consciousness. Utopias are ultimately realizable ideas and programs, while ideological ones are not (Walters, 1989). The problem with this view is that we must wait until the end of history to identify which is which, a situation that questions the usefulness of the criterion (Alexander, 1984). Davis' typology allows us to identify and understand types of ideal society by their commonly occurring features. They are, in Max Weber's (1947) sense "ideal-typical" categories; that is, they are approximations that permit variety. They are not intended to pinpoint but rather guide our thinking about the history of ideas concerning the ideal society. 
Davis $(1981,1984)$ outlined the social and political features of five types of ideal society: cockaygne, arcadia, moral commonwealth, millenium, and utopia. I will examine each of these in turn and assess their applicability to the society reported in transcendental NDE states.

\section{Cockaygne}

The cockaygne society has been described as the "poor man's paradise." This type of society exists in idyllic physical surroundings and material privileges and sensual gratification. Every whim and appetite is instantly and handsomely satisfied. A desire for food is immediately met by banquets of desirable items, which may be chosen on overloaded and groaning tables or fed directly into one's mouth without effort. Sexual desire is catered for by the instant appearance of beautiful, willing, and most able partners. The "Land of Cockaygne" was most prominent as a set of ideas about the ideal society around late medieval Europe (Davis, 1981).

Davis $(1981$, p. 21) cited a marvelous poem from the period that amply illustrated the spirit of cockaygne:
Ah, those chambers and those walls!
All of pasties stand the walls,
Of fish and flesh and all rich meat,
The tastiest that men can eat.
Wheaten cakes the shingles all,
Of church, of cloister, bower and hall.
The pinnacles are fat puddings,
Good food for princes or for kings.
Every man takes what he will,
As of right, to eat his fill.
All is common to young and old,
To stout and strong, to meek and old.

The poem ends with the final message about work and payment.

Every man may drink his fill and needn't sweat to pay the bill

In cockaygne, the vision of ideal living is largely an escapist peasant one. In this respect, freedom from work and hunger are the main obsessions. The medieval social order is reversed in cockaygne, where peasants enjoy unrestrained decadence and the upper classes toil chin- 
deep for years in dirt and filth before they are able to indulge in any pleasures. The social order is maintained because appetites are always satisfied rather than because the basic organization of society has altered.

The transcendent society has some environmental similarities with cockaygne. It is a place that is perpetually beautiful and garden-like. In the transcendent society, as in cockaygne, there is no death. However, in cockaygne total wish fulfillment prevails.

Although many needs are apparently gratified in the transcendent society, there are no reports of cockaygne-like indulgence. In fact, except for the occasional report of fruit on trees, food appears conspicuous only by its absence (Brookesmith, 1984). Also difficult to locate in modern accounts of NDEs are any descriptions of sexual activity. If eating and sexual activity were as prominent in the transcendent society as cockaygne, the difficulty of locating these accounts would indeed be unusual. Finally, the cockaygne life is an idle one, without work or care for it. The transcendent society is one, however, where work is a conspicuous feature of social life. Buildings and service to others do not "just happen" but are provided for by fellow beings who fully plan and participate in the processes of this work. Clearly the transcendent society is no cockaygne.

\section{Arcadia}

The arcadian society is a cockaygne-like society with restraint. Set in idyllic surroundings once again, human beings display their dignity through exercising their moral and aesthetic sense. This restricts appetite, and so abundance is temperate and somewhat modest in comparison to the "Land of Cockaygne." In a society of plenty people nevertheless do not overindulge but rather satisfy their needs, such as they are. We can also observe some of this feature in the transcendent society. Grey $(1985$, p. 54), for example, cited the meeting of one NDEr with his deceased mother.

I found myself standing in front of a nice prefab (inexpensive and prefabricated dwelling that can be erected very quickly and was extensively used during World War II to house bombed out victims). There was a path leading up to the front door with masses of nasturtiums on either side. The door was open and I could see my mother inside. I thought, "That's funny, my mum always wanted a prefab and she always loved nasturtiums." 
It is not important here to ascertain in whose mind the prefab/ nasturtium existence was truly ideal, the NDEr or his mother. It is sufficient only to note that basic desires are being fulfilled in this transcendent society. People's needs are being met, but not disproportionate to their desires, and their desires seem appropriate to their former lives and backgrounds. However, once again, the arcadian existence, largely inspired by romantic, medieval notions of primitive life in the New World, is largely an idyllic life (Davis, 1981). Work is not an integral and socially important activity for arcadia, and yet it is for the transcendent society.

\section{Perfect Moral Commonwealth}

In this type of ideal society, people apply more restraint on themselves, tolerate some hardship, and basically want for the greater good. In the idea of the moral commonwealth is found the first major social shift away from the self and its needs, toward the needs and welfare of the wider community. The notion of regulation is formally introduced as an integral and important part of this ideal society. As the name implies, the whole wealth and work of every individual must be dedicated to the common good (Davis, 1981).

The philosophy and sociology of the moral commonwealth turns on the idea of moral individualism. This kind of society does not depend on structural reorganization but rather the willingness of individuals to do their duty. Moral rearmament of the individual rather than changing the political and social system brings about the ideal, harmonious society. Control and regulation is contained within the individual. The problem of evil and deviance is inextricably bound up with the problem of personal discipline and values (Davis, 1981).

In the near-death experience, the values of personal change and moral development are encouraged in the transcendent society in a context of social support, human warmth, and love. Nevertheless, the transcendent society has apparently not left its organization dependent on the combined efforts or willingness of individuals to maintain its order. Social regulation is clearly evident and, unlike some examples of the moral commonwealth (Davis, 1981), magistrates are not redundant (Counts, 1983).

As described by Lundahl (1981-82, pp. 323-24), formal sanctions are enforced and, although there exist many "self acting and self thinking" individuals, more than a few people are restrained, presumably against their will. A governing order that exerts some sort and degree 
of authority and control acts as a regulatory social system. This is clearly a system that takes deviance for granted and does not expect uniform moral restraint by all individuals, at least initially. The moral commonwealth model of ideal society, dependent as it is on individual moral restraint, does not appear to be the basis of the transcendent society.

\section{Millenium}

The ideal society of the millenarians is one where human beings and nature itself are transformed by apocalyptic forces external to both. After purging of the manifold problem features and groups within humanity a new world order emerges (Davis, 1984). Linked closely to the history of Christianity, the apocalyptic event is commonly Christ's Second Coming. However, the millenium applies to any religious movement and is an ideology of salvation that stresses perfection on earth facilitated by supernatural beings (Davis, 1981). In social terms, the transcendent society is least like the millenarian society.

First, the appearance of the transcendent society is not linked to any ideology of salvation. That is to say, entry into that ideal form of society is not dependent on membership in any religious movement. Second, perfection on earth is not stressed. The transcendent society is an order that exists beyond, but alongside, our own, and does not represent a future transformation of our own time and place. Furthermore, the transcendent society does not itself assume human perfection, as my earlier remarks about deviance and control suggest. Rather, moral and social evolution is assumed to be a process that may begin on earth, definitely continues in the transcendent society, and may be completed there in some distant and unclear time and place within that society. Finally, the role of supernatural beings in the transcendent society is different from that in millenarian conceptions. Some NDErs do observe, or believe they observe, religious figures in the transcendent world but these are often simply guides, life review facilitators, or part of a welcoming party. Some apocalyptic changes have been forecast for our world and its societies (Ring 1984, 1988), and some of these have suggested a new emerging order. This order, however, has never been confused or identified with the transcendent society of the NDE. That society apparently remains distinct and otherworldly.

The transcendent society is not a millenarian society though some who visit there may bring the occasional millenarian message. Mille- 
narians search for meanings in personal experience and the world around them like everyone else. But unlike many others, millenarians often find this meaning in ideas about the afterlife, in what John Harrison (1984) described as "Holy Utopias." The path to this utopian vision is through apocalyptic and supernatural intervention. For the NDEr the path to the ideal society is simply and less dramatically through death. This notwithstanding, the paths of millenarians and NDErs may often converge, even when their purposes and ideas are not always the same (Harrison, 1984).

\section{Utopia}

According to Davis (1981), utopias may be distinguished from other forms of ideal society by their approach to the problem of human willfulness, deviance, and unlimited appetite. In utopia there is no wishing away of problems as in cockaygne. Nor is there at the center of utopian vision and planning the need for a great purging, as in the millenium. Rather, social systems must be designed to take account of social problems such as crime, hostilities, and exploitation. Organizations must provide education and social control to enable the collective to attain greater good and harmony, but also to keep checks on the incorrigible, the corrupt, and the slack. As Davis (1981, p. 38) observed,

The perfect moral commonwealth tradition idealises man (sic). The land of cockaygne idealises nature, in an admittedly gross way. In Arcadia, too, nature is idealised but at the same time man is naturalised. In utopia, it is neither man nor nature that is idealised but organisation. The utopian seeks to 'solve' the collective problem collectively, that is by the reorganisation of society and its institutions, by education, by laws and by sanctions.

Utopias are total physical and social constructions, total environments, whose goals are social order and the ultimate perfection of humanity through collective effort. This is quite a good description of the transcendent society described in so many NDEs.

As Lundahl (1981-82) has remarked, the transcendent society emphasizes harmony and organization. Order in both moral and social terms is the hallmark of that society. Education and social control of deviance is commonplace. Education, as a formal place for gaining knowledge, frequently takes place in classroom-like settings similar to our own societies. Learning, in both formal-educational and informalsocialization senses, is an important feature of the transcendent soci- 
ety. As in most utopian visions, people are free agents, but this is a freedom from disorder and moral chaos. The citizens of utopian societies are not free to do as they please, if this means creating confusion or doing wrong things to others (Davis 1981 p. 388).

Another way in which these values and images of the transcendent society are utopian is their function as social criticism. Utopian thought is always, partly at least, a rejection of the contemporary world and its processes (Davis, 1984). They contribute to a "climate of opinion" (Goodwin, 1984) that stimulates others to take up the policy, theory, or social action. In this respect, the basic organization of the transcendent society conveys value systems that are utopian. Values important to NDErs, such as cooperation, humanism, and self development, are implicit criticism of other values such as competition, selfishness, and authoritarianism. Utopian values display and highlight rather than supply a specific outline of a new morality. They are inspirational rather than prescriptive.

The transcendent society, and the tales from there, act as narratives by which we may orient ourselves, our cultures, and our roles and ambitions within them. In these ways, utopias are to adults what fairytales are to children (Alexander, 1984). They draw on current feelings and problems about the world and inspire both audiences to higher things, without ever becoming a dense legislature. This is a commonly observed role for utopian imagery (Bloch, 1988). This inspirational role makes utopias responsible for introducing, or renewing, a new and better set of human values. In the case of the transcendent society where the values are simply learning, love, and service, the task may arguably be one of renewal and revision.

The importance of promoting harmony, of cooperation and love, are the chief characteristics of social intercourse in the transcendent society, as indeed they may be with NDErs themselves. In these above respects the transcendent society, or what little we know about it, seems to meet Davis' general criteria for a utopian society. In these terms, the transcendent society is a total physical and social environment whose goals are human perfection, social order, and harmony. Furthermore, like Thomas More's Utopia, it is a society supposedly already in existence rather than being a prescriptive or futuristic entity. In this respect, the transcendent society belongs to that tradition of literature where a person or group of travelers stumble by accident upon another society. Their accounts simply describe what they see, experience, and do along with their incredulity and admiration (Kumar, 1987). In this tradition of utopian literature, these places often have cities of "a structurally fabulous kind," "miraculous trans- 
port and strange animals and people" (Alexander, 1984, p. 37). The transcendent society is characterised by many of these features too, but it is nevertheless not simply and merely a utopian society like many before it. On the contrary, the transcendent society is a utopian society with several unique features.

\section{A Unique Utopia}

If the transcendent society is utopian it is no ordinary utopia within the strict terms by which Davis outlined his typology. It is true that social organization and values of the transcendent society are utopian in their regulation of work, deviance, and education. In this respect, the social organization is the chief agency of socialization and control. However, the need for individuals to take responsibility for the shaping and nurturance of their own values is also strongly present. This is, for example, a common idea running through NDErs' reviews of their lives both during and after their NDEs. This social dimension of the transcendent society is somewhat akin to the prescriptions of the moral commonwealth.

Although utopia's main task is the transformation of humankind, nature also seems perfected and idyllic in the transcendent society. Here we witness elements of cockaygne. But restraint does co-exist with the satisfaction of a wide and mixed array of needs and, in this respect, there exist elements of arcadia. Although the transcendent society is not millenarian, we have also noted millenarian elements that overlap, particularly the pareschatological direction and dynamism that NDErs and millenarians draw upon for their images.

So the transcendent society is utopian but, as it were, in a simple postmodern sense (Bradbury, 1988). It has a postmodern style first because, as I have demonstrated, the transcendent society is a pistache of previous conceptions of the ideal society, and features these as important parts of its own structure. Second, the transcendent society as utopian imagery is critical of some modern values (e.g. competition, materialism) while co-opting and promoting others (e.g. humanism, spiritualism) (Zaleski, 1987). Finally, the transcendent society as utopia is, because of its eclecticism, able to reconcile criticism and paradoxes that often confronted other utopias. Other modern utopias experienced tensions between rampant individualism (e.g. benevolent despotism, divine rule) and mindless collectivism (e.g. Orwellian totalitarianism). Cultural development often occurred together with its destructive consequences for nature. However, the transcendent soci- 
ety is a utopian society where social control is tempered and tamed by individualism so that Big Brother does not convert one person's utopia into another's dystopic nightmare. Work and cultural development help transform people while the world of flowers and brooks remains Eden-like, maintained and protected in some mysterious way from the usual ravages of damage and exploitation.

The images of the transcendent society in the NDE stimulate a sense of interconnectedness in NDErs and those who read or hear their stories. These images appear to overcome the contradictions and problems associated with the worlds of spirit, culture, and nature. The tensions between culture and nature are reconciled in the arcadian images of people appreciating the effect of their own needs on each other and the environment. The value of restraint is learned in the context of a new appreciation of the interconnectedness of human action within the social and physical universe. The many attempts to explain the NDE as a human experience have also seen several attempts to bridge the perceived gap and tension between religious and scientific paradigms (Zaleski, 1987; Fenske, 1990).

This is a special type of utopia, essentially utopian in a modern sense but at the same time featuring social elements from many ideal societies favored and pursued in the past. Because of these features, the transcendent society is able to field common criticisms of utopias by overcoming contradictions that have plagued other conceptions. Little wonder the transcendent society and the NDE in general have captured the popular imagination. In this important way NDEs have reawakened the pursuit of the ideal society after nearly a century of collective pessimism. This historical characteristic makes the transcendent society unique in another way.

As utopia, the transcendent society represents a very special type of ideal society emerging, or reemerging, as it does, in the late twentieth century. This is because, as Kumar (1987, p. 380) observed, this century has been host to the claim that "utopia is dead." There have been too many events this century that have dampened optimism and discouraged utopia. The world wars, Nazism, Stalinism, Pol Pot, Hiroshima, the Cold War and the arms race, and recently the collapse of Eastern Bloc Communism have battered and dismantled the earlier romantic visions of nineteenth century utopian writing.

Despite this, some utopias have survived, for example, the kibbutzim, science fiction utopias, and New Age consciousness writing. Among other developments, the writings of Marshall McLuhan, Timothy Leary, Herbert Marcuse, Charles Reich, and Ivan Illich have all served the sporadic and apparently indomitable pursuit of the ideal 
society. Within the darkened recesses of twentieth century pessimism these experiments and writings have supplied, or attempted to supply, new ways of resolving the problems of living with the urban industrial cultures of modernity.

But Kumar (1987) argued that these have not become the central symbols for society but rather have flourished as specific visions for specific groups. Certain cults, communes, social movements, and types of social theory have been peddlers and adherents of these various utopian inspirations.

Here, however, Kumar overstated his case, confusing the lack of popularity with the problem of cultural representativeness. It is true that many of the utopian visions this century have been group specific in their attractions. However, the pursuit of alternative utopian visions as a generalized pursuit in itself has in fact been widely representative, but in a special sense. Although twentieth century utopias have often not been representative in the content of their social ideas, they have been in the sense of their creative source. There has been a widespread dissatisfaction with modern social conditions and values, and consequently a pursuit of better. Products of this discontent can be seen in the steady growth and acceptance of feminist, environmentalist, self-sufficiency, prodemocracy, and social network ideas, and their impact in the spheres of politics, the workplace, and family and household, to name only a few. In this respect, utopias as forms of alternative social knowledge actually depend for their very appearance upon a widespread dissatisfaction with the existing world (Walters, 1989). This complements Zaleski's observation (1987) that NDEs occur most when cultures cause social and moral dislocation and there develops a widespread need for orientation. So the revision that must apply to the received twentieth century wisdom that "utopia is dead" is simply that lately this century, a widely attractive utopia has been difficult to discern. However, the widespread desire and pursuit of utopian social ideas are alive and well and historically accounted for.

In this context, the transcendent society is an exceptional utopia not because its images and values draw from this same source of social discontent but rather more remarkably because these images do not arise from any one social group. Furthermore, despite some cultural variation in NDE imagery, the basic organization and ideas of the transcendent society remain fairly stable. Village huts that float above the ground (Counts, 1983) may indeed replace cities in some versions of the transcendent society, but the values of order, cooperation, kindness, and learning appear to be stable, at least widely reported, ideas.

As such, the transcendent society as utopia provides a set of ideas 
widely representative in aspiration and constitution. It is therefore widely appealing as an ideal form of society. Furthermore, the rise and popularity of NDE imagery in industrial societies suggests and highlights a general dissatisfaction with the depersonalizing and alienating conditions within them. For those who have not experienced an NDE, this imagery becomes a rich kind of thought exercise (Alexander and Gill, 1984) or "mode of visualising" (Davis, 1981, p. 370) that fires the social imagination. To place this observation within the utopian discourse is to say that it is conceivability of the ideas and values rather than the achievability of any actual social system that becomes important (Alexander and Gill, 1984). The traditional debate over the realizability of utopias is not as important here. As Peter Beilharz (1989) observed, one of the social functions of utopian social ideas is to sharpen our understanding of current political and moral dilemmas. It is this function that may characterize and take precedence in a postmodern form of utopia such as the transcendent society.

\section{Conclusion}

Zaleski (1987) argued that NDEs are not widely attractive utopias. Rehearsing a similar argument to Kumar (1987), Zaleski believed this is because NDEs are unable to be a widely shared basis for a new philosophy. This, in turn, is due to a lack of symbolic power wider traditions such as medieval NDEs once had. But Zaleski underestimated the attraction of NDEs to wider social movements stimulated by rapid and disruptive social changes that had their beginnings in the Industrial Revolution. These changes have continued to fragment and disorientate through two world wars and innumerable domestic and international conflicts and divisions. In this context, many have overlooked the possibility that the attracting power in NDE may indeed be part of a wider tradition, the pursuit of the ideal society.

A long tradition, in evidence in national politics and religion, social theory and social movements, the pursuit of the ideal society bloomed in the romantic climate of nineteenth century western idealism. The course of the twentieth century has seen utopia as a social idea and experiment falter as people exchanged hopes of harmony for peace, and then hope of peace for mere tolerance. But the obstacles to a widely attractive set of utopian images were also ironically the driving incentive for the continuation of its pursuit, albeit in small but important social experiments, in less popular but no less influential social theory and literature. The modern challenge confronting utopias has been the 
development of a set of images that might cross different social groups and boundaries but might nevertheless inspire and unite each in similar ways.

The transcendent society appears to be a utopia whose features can be seen as attractive to a whole array of different groups and, as I have argued, this may be one reason for the popularity of NDEs. Despite this popularity, the transcendent society may not be a high profile utopia, offering as it does only a pocketful of assorted and simple values and very little in the way of social programs and policies. To our recently dark notions of death, and in our pursuit of the ideal society against the even darker cynicism of our times, the ideas of the transcendent society may appear only as dim candlelight. But in beginning the long task of rebuilding optimism and a shared view of a better society, that may just be enough.

\section{References}

Alexander, P. (1984). Grimm's utopia: Motives and justifications. In P. Alexander and R. Gill (Eds.), Utopias (pp. 31-42). London, England: Duckworth.

Alexander, P., and Gill, R. (Eds.). (1984). Utopias. London, England: Duckworth.

Becker, C.B. (1981). The centrality of near-death experiences in Chinese Pure Land Buddhism. Anabiosis: The Journal of Near-Death Studies, 1, 154-170.

Becker, C.B. (1984). The Pure Land revisited: Sino-Japanese meditations and near-death experiences of the next world. Anabiosis: The Journal of Near-Death Studies, 4, 51-68.

Beilharz, P. (1989). Utopia and its futures. Thesis Eleven, 24, 150-160.

Bloch, E. (1988). The utopian function of art and literature: Selected essays. Cambridge, MA: M.I.T. Press.

Bradbury, M. (1988). Post-modernism. In A. Bullock, S. Trombley, and B. Eadie (Eds.), The Harper Dictionary of Modern Thought. New York, NY: Harper and Row.

Brookesmith, P. (1984). Life after death. London, England: Orbis.

Counts, D.A. (1983). Near-death and out-of-body experiences in a Melanesian society. Anabiosis: The Journal of Near-Death Studies, 3, 115-135.

Davis, J.C. (1981). Utopia and the ideal society. Cambridge, England: Cambridge University Press.

Davis, J.C. (1984). The history of utopia: The chronology of nowhere. In P. Alexander and R. Gill (Eds.), Utopias (pp. 1-17). London, England: Duckworth.

Elder, B. (1987). And when I die, will I be dead? Sydney, Australia: Australian Broadcasting Commission.

Fenske, E.W. (1990). The near-death experience: An ancient truth, a modern mystery. Journal of Near-Death Studies, 8, 129-148.

Gallup, G., Jr., and Proctor, W. (1982). Adventures in immortality: A look beyond the threshold of death. New York, NY: McGraw-Hill.

Goodwin, B. (1984). Economic and social innovation in utopia. In P. Alexander and R. Gill (Eds.), Utopias (pp. 69-83). London, England: Duckworth.

Grey, M. (1985). Return from death: An exploration of the near-death experience. London, England: Arkana.

Greyson, B. (1985). A typology of near-death experiences. American Journal of Psychiatry, 142, 967-969. 
Harrison, J.F.C. (1984). Millenium and utopia. In P. Alexander and R. Gill (Eds.), Utopias (pp. 61-66). London, England: Duckworth.

Hermann, E.J. (1990). The near-death experience and the Taoism of Chuang Tzu. Journal of Near-Death Studies, 8, 175-190.

Kellehear, A. (1990). The near-death experience as status passage. Social Science and Medicine, 31, 933-939.

Kumar, K. (1987). Utopia and anti-utopia in modern times. Oxford, England: Blackwell.

Lindley, J., Bryan, S., and Conley, B. (1981). Near-death experiences in a Pacific Northwest American population: The Evergreen study. Anabiosis: The Journal of NearDeath Studies, 1, 104-124.

Lundahl, C.R. (1981-82). The perceived otherworld in Mormon near-death experience: A social and physical description. Omega, 12, 319-327.

Mannheim, K. (1960). Ideology and utopia. London, England: Routledge and Kegan Paul.

Manuel, F.E., and Manuel, F.R. (1979). Utopian thought in the Western world. Oxford, England: Blackwell.

Moody, R.A., Jr. (1975). Life after life. Covington, GA: Mockingbird.

Moody, R.A., Jr. (1988). The light beyond. New York, NY: Bantam.

Pasricha, S., and Stevenson, I. (1986). Near-death experiences in India. Journal of Nervous and Mental Disease, 174, 165-170.

Ring, K. (1980). Life at death: A scientific investigation of the near-death experience. New York, NY: Coward, McCann and Geoghegan.

Ring, K. (1984). Heading toward omega: In search of the meaning of the near-death experience. New York, NY: William Morrow.

Ring, K. (1988). Prophetic visions in 1988: A critical reappraisal. Journal of Near-Death Studies, 7, 4-18.

Sabom, M.B. (1982). Recollections of death: A medical investigation. New York, NY: Harper and Row.

Walters, K.S. (1989). The sane society ideal in modern utopianism. Toronto, Ontario: Edwin Mellen Press.

Weber, M. (1947). The theory of social and economic organization. New York, NY: Free Press.

Zaleski, C. (1987). Otherworld journeys: Accounts of near-death experience in medieval and modern times. New York, NY: Oxford University Press. 